\title{
Hypnotherapy in a Cancer Patient
}

\author{
Walter Tschugguel \\ Universitätsklinik für Frauenheilkunde, Medizinische Universität Wien, Austria
}

Key Words

Hypnotherapy · Phenomenology · Paradigm · Cancer

\section{Summary}

Background: The case of one single session of hypnotherapy in a female patient suffering from metastasised breast cancer is presented. The case presentation is followed by a short overview of the phenomenology and potential mechanisms of hypnosis. Case Report: A terminally ill, 43-year-old female patient with breast cancer and metastases in liver, bones, and brain was presented to the author. The patient suffered from anger, sadness, and strong pain in her whole body, most tormenting in both forearms. A single 35-minute session of hypnotherapy was performed. This resulted in the patient's being in a good mood and feeling an urge to get up from bed, move around on the ward and leave the breast cancer unit as soon as possible to organise all important issues at home with her family and friends. Conclusion: A single session of hypnotherapy was effective in motivating a terminally ill patient to accept responsibility for her own, private concerns. Hypnosis is an altered state of consciousness that remains to be fully understood from the conventional empiric social psychology and neurobiology research paradigm.

\section{Introduction}

First, this article demonstrates how one single session of a psychotherapeutic procedure, referred to as 'hypnotherapy', can be applied to a terminally ill patient with metastasised breast cancer. The description of procedures provided here is fol-

\author{
Schlüsselwörter \\ Hypnosetherapie · Phänomenologie · Paradigma · Krebs
}

\section{Zusammenfassung}

Hintergrund: Die Kasuistik einer einzelnen Hypnosetherapie-Sitzung bei einer Patientin, die an metastasiertem Mammakarzinom litt, wird präsentiert. Daran schließt ein kurzer Überblick über die Phänomenologie und mögliche Mechanismen der Hypnose an. Fallbericht: Eine terminal kranke, 43 Jahre alte Patientin, mit metastasiertem Mammakarzinom bei nachgewiesenen Leber-, Knochen- und Hirnmetastasen, wurde dem Autor vorgestellt. Die Patientin litt unter Zorn, Traurigkeit und heftigem Schmerz in ihrem gesamten Körper, wobei der Schmerz in beiden Unterarmen am stärksten war. Eine einzige, 35 Minuten dauernde Hypnosetherapie-Sitzung wurde durchgeführt. Dies führte dazu, dass die Patientin guter Stimmung war und das Bedürfnis verspürte, ihr Bett zu verlassen, herumzugehen und möglichst bald die MammakarzinomStation zu verlassen, um zu Hause mit ihrer Familie und ihren Freunden alle wesentlichen Angelegenheiten zu organisieren. Schlussfolgerung: Mit einer einzigen Sitzung Hypnosetherapie konnte eine terminal kranke Patientin motiviert werden, die Verantwortung für ihre eigenen, privaten Angelegenheiten zu übernehmen. Hypnose ist ein veränderter Bewusstseinszustand, der mithilfe der üblichen empirischen sozialpsychologischen und neurobiologischen Forschung nicht komplett erklärt werden kann.

lowed by an explanation in order to understand the rationale for choosing them. Second, a short description of the phenomenology and of potential mechanisms of hypnotherapy is provided to understand the theoretical concepts that are accepted for the time being.

\begin{tabular}{|c|c|}
\hline KARGER & (C) 2007 S. Karger GmbH, Freiburg \\
\hline $\begin{array}{l}\text { Fax +49 } 7614520714 \\
\text { E-mail Information@Karger.de } \\
\text { www.karger.com }\end{array}$ & $\begin{array}{l}\text { Accessible online at: } \\
\text { www.karger.com/brc }\end{array}$ \\
\hline
\end{tabular}

Prof. Dr. Walter Tschugguel

Universitätsklinik für Frauenheilkunde

Medizinische Universität Wien

Währinger Gürtel 18-20, 1090 Wien, Austria

Tel. +43 1 40400-7828, Fax -7842

E-mail walter.tschugguel@meduniwien.ac.at 


\section{Case Report}

A terminally ill, 43-year-old female patient suffering from metastasised breast cancer with metastases in her liver, bones, and brain was presented to the author during his weekend attendance on the ward. According to the nurses and colleagues, the patient was agonized, unable to move, unwilling to speak more than absolutely necessary both with the medical personnel as well as with her family, and presented with anger, sadness, and pain in her whole body, most tormenting in both forearms. For several months she had received increasing dosages of non-steroidal analgesics, tramadol as well as high-dose opiates. However, the pain killers appeared to be ineffective.

In the following paragraph, the ideas behind the presented procedures are given. For the sake of clear understanding, the specific sentences provided by the author within the hypnotic relationship with the patient are presented in italics. The respective ideas behind these sentences are given subsequently and marked by an ' $R$ ' for rationale.

First, the author asked the patient whether she will allow him to take a seat at the bedside beneath her left side. R: A patient who is asked to allow something to another person implicitly knows that she can decide freely whether to permit or not. This conversational postulate offers an idea of deliberateness in any of the patient's decisions combined with the cultural background that permission will be offered to the therapist in most instances. This attitude, thus, increases the probability for a good relationship between the patient and the operator, a procedure called 'rapport' in hypnotherapy. As a confirmation of the patient's acceptance, she agreed to the author to take a seat by her side by uttering a surprised but vague laughter.

She was next asked whether she will put herself into a position that is really comfortable to her, while the author made himself comfortable at the bedside. R: The use of the phrase 'really comfortable' opens the idea of comfort to her, comprising both explicit sitting comfort with implicit comfort in many other life situations, if the phrase is spoken a bit slower than usually and with some connotations of manifold ways of comfort the operator has meanwhile in mind. However, these connotations cannot reach her conscious mind due to the simultaneous and superficial talk about comfort sitting in her bed. I.e., the connotations are free from conscious rationalisation attempts and can, thus, act unhinderedly on an unconscious level.

The author casually added that she can change her position whenever her body will require a new position, while he moved into a comfortable sitting position beneath her. R: While explicitly meaning that she can change her sitting position, the somewhat vague formulated above-mentioned sentence is a very effective means of suggesting to her unconscious mind to have the full and competent authority to induce any changes in her behaviour, attitudes, and communication. However, by nodding her head with a confused facial expression she accepted not only the conscious conversation but also the implicit meanings of the sentence by drifting into trance. This behaviour was reflected by blinking of her eyes and fluttering of her eyelids, which are well-known trance phenomena.

The author utilised her behaviour by decreasing the speed of his voice, restricting his speech to the expiration phase of the patient's breathing rhythm, and by inviting her to ask herself how long her eyelids will flutter (pause) until feeling an urge for closing [1]. R: The above-mentioned procedures are trance inductive. The question how long a process will take until something, i.e. closing the eyes, will occur is a so-called double bind communication, invented by Milton Erickson for putting a given individual in a situation to freely choose between several positive and well acceptable alternatives [2]. These alternatives are to either close her eyes right now or some moments or minutes later. Whatever is chosen unconsciously by the patient will be accepted by the operator. Accordingly, she closed her eyes within the next 2-4 minutes.

She was subsequently asked what pleasant experiences her closed eyes trigger within what side in her body (pause) or person (pause) first? R: Here, the reader finds a mixed double bind communication by the ques- tion what pleasant experiences her closed eyes trigger within what side in her body, implicitly meaning that there is no question of whether pleasant experiences will occur, but only of which exact nature they are and in which site of her they will start to spread first. Here, the author again introduced a new double bind by dissociating artificially into an entity he named body by directing his voice downwards to the floor and another entity he named person by directing his voice upwards toward the ceiling. This is an implicit means to suggest dissociation between different parts of the patient, what is mostly associated with a huge difference between the explicit culture- social- and family-system derived behaviour and the own inner wishes, desires, and demands expressions. I.e., such dissociation allows the patient to move freely with an instance called person toward goals and ambitions that reflect her own real urges and needs and are, thus, mostly accompanied with very pleasant feelings. She responded, accordingly, by going deeper into trance.

The author responded to her slight idiomotoric body movements by utilising them. In particular, he added that the voice of her stomach invites her to go deeper into trance, that slight movements of her fingers invite her to go deeper into trance, that her breathing rhythm has changed, that her heart rate has changed, that her blood pressure has changed, while watching a deepening of her breathing rhythm and a decrease of her carotid pulse speed. R: The Erickson's utilization principle means that any presenting behaviour a given patient demonstrates is initially and fully accepted by the operator, however seemingly adverse it may appear to be in the clinical situation [3]. In practice, the operator defines autonomous behaviour, i.e. shuffling of the gut, slight spontaneous finger movements, breathing changes, heart rate changes, nodding of the head, etc. as substrates for trance induction, trance-deepening purposes, or processes of change.

The author further asked in a very slow way how many degrees of freedom her person (voice directed upward) is willing to experience now, while her body goes deeper into trance (voice directed downward)? R: The dissociation status is secured by spatially directing further questions to either her person or her body. A double bind question is directed toward her person by implicitly stating there are at least two degrees of freedom by using the plural. Moreover, the idea of freedom means to proceed in any direction she unconsciously wishes to proceed in her doing and thinking, a process she is willing to experience now, which is secured by mental or bodily sensations right in that moment. These experiences can further be utilized by functionalising them as substrates for further trance deepening of her body.

The author asked her in a very slow voice 'how bothersome it might be for the farmer if grains of seed the farmer lost through a gap of his granary are, grain by grain, picked up by the birds'. R: The term bothersome allows her to turn aside her resistances and anger via a casually narrated metaphor about a leaky farmer's granary, thereby reflecting metastasised disease, but as nature can play the grains or metastases can be picked up by the birds. This story can either be accepted unconsciously or has at least no impact on her mind. She wrinkled her forehead and went deeper into a stuporous trance, what could mean that at least some part of the story reflected her unconscious assumptions and ideas regarding the nature of her disease. However, she also could have responded to the calm and slow voice or the pauses between the author's sentences, words, or syllables without reflecting the contents of the story. Thus, any operator should be cautious to interpret the patient's behaviour too easily to prevent him from following the operator's ideas. The one and only issue is that the operator creates an atmosphere in which the patient's own presumptions, ideas, and reflections can grow and, consequently, can get access to her behaviour.

The author further asked her to move her right digit finger as soon as her body was informed by her unconscious mind from which part within her body feelings of warmth, or tingling or completely different sensations have started to spread first. R: These are questions that are able to unconsciously re-structure and organise her thoughts, by utilising the dissociation status and the idiomotoric movements of parts of her body as substrates for 
further spreading of pleasant feelings as unequivocal reactions out of double bind questions.

Did these feelings start from her left side or her right side (pause), first? And what has to be added to the left side to be complete on her right side? $\mathrm{R}$ : Confusion arises by putting the directions left and right together with the implicit postulate that there is something unknown between the right and the left side of her body what makes her in some way complete, thereby initiating an inner search process for pacing an idea of secrets behind her explicit body. Secrets are part of any individual's nature and can, thus, be incorporated into a process of change. Following some more minutes in trance, while the author further utilised her idiomotoric behaviour to let her experience a more profound deepening of her trance state, he suggested to her that as a function of her unconscious mind she exactly knows how and where to proceed below the surface of her conscious mind, who can do or not do whatever she wants to do or does not want to do, which is of major importance to her. R: Here, the author puts all mental processes into her own responsibility by stating that only she knows how and where to proceed. By adding respective negations, potential resistances and ambivalences, making her angry and sad, are turned aside. This firm and definite unconscious knowledge will allow her to experience a slight, inner laughing after she will have been woken up freshly and with surprising feelings. R: Firm and definite are words to increase her trust into the process of change what made her laughing and waking up as responses that are implicitly contingent upon her firm and definite knowledge. I.e., by realising that she really woke up freshly and with slight laughing she implicitly knows that she only could have woke up as a function of a deep and secure knowledge of mental change.

This unconscious knowledge will further let her forget to remember or remember to forget (pause) what is the mixture of the colours green and orange? R: This is a classical double bind statement suggesting that in any instance she will forget most parts of trance contents and ideas for the sake of unconscious working without any conscious and, thus, intellectual doubt of success. In addition, these amnesia suggestions are simultaneously separated by the pause between the words forget and the subsequent amnesia reinforcing question, what the mixture of green and orange $i$, as well as pseudo linked to this question. Thus, the patient does not know whether she is invited to forget trance contents or to forget the mixture of both colours that, per se, contain hopeful connotations, i.e. green from fresh and healthy plants and orange from the warm sunlight. However, these connotations can be utilized for sake of amnesia or even with connotations different from those given by the author.

The unconscious knowledge to proceed is the ground of waking up freshly and with surprising feelings within the next 30 or 35 breathings after she will have experienced an urge to stretch her arms to freshly wake up as if she had slept for a whole night. R: Once again waking up freshly appears contingent as a function of an unconsciously initiated process of changing her attitudes and subsequent behaviour, which raises enormous bodily comfort by suggesting as if she had slept for a whole night.

The patient awoke with a slight laughing on her face, stretched herself by sitting up in her bed in an upright position, and remained sitting there in a somewhat confused mood. The author left the room without further talking to her. Three hours later the author was asked by the nurse if he would support her sudden wish to leave the breast cancer unit immediately; she stated to the nurse that she had so many things to organise at home and with her family and friends. When the author met the patient at the unit, he was surprised; he found her with a slight laughing on her face walking speedily through the unit due to her impatience to be discharged. She had no further questions despite being carefully asked for them, in particular for potential pain. She left the unit as soon as she received the author's undersigned dismissal documents.

In conclusion, one 35-minute session of hypnotherapy performed in a patient in death agony, suffering from metastasised breast cancer and overall pain helped the patient to overcome agony and seemingly most of her pain, so that she could act and organise all important issues. It is important to note that the only specific therapeutic goal of the author was to im- plicitly motivate her to activate inner potentials and mechanisms in order to get rid of her pain and associated suffering. No further information was available about the follow-up of this patient. Whether or not such a procedure can, in individual and select cases, be of potential help in the remission of disease, cannot be answered by the author to date.

\section{Phenomenology of the Hypnotic State}

The state of hypnosis $[4,5]$ is currently regarded as an altered state of consciousness [6, 7], which appears to be experienced $[8,9]$ as well as objectified [10] distinct from ordinary waking behaviour. Thus, hypnosis can be described both from a hypnotised first person's view with the researcher as a personal union of investigator-participant and more conventionally from the hypnotised subject's reports as well as from neurobiological evidence $[4,8,11]$. In particular, the experiences obtained from the first person's view mostly comprise a state of relaxation and mental ease, absorption, orientation and monitoring, and self-agency [8]. A more lively description was provided in earlier years by Milton H. Erickson [12]. ' ... Hypnosis is not something that you do to the patient. It is something that occurs within the patient' and '... you offer suggestions not as the thing the patient has to do, but as a stimulus to elicit patient behaviour in accord with their own body learning ...' In other words, hypnosis occurs by altering the paradigm of communication between the patient and the doctor from an outward to an inward orientation. 'During that process of introspective thinking, the patient would go into a trance state' [12]. 'You as the doctor want the patient to do whatever kind of thinking that allows that patient to get within him- or herself. You present ideas to the patient in such a way that you satisfy his or her needs. You present ideas that the patient could find acceptable, but you do not ask him or her to accept those ideas.' Consequently, 'the trance state reality exists, and it is there, but it is not really important.' Thus, 'the best test of hypnosis is the reaction of the individual to the total environment and how the external reality affects the individual and how he or she responds' [12].

\section{Paradigm of the Hypnosis Mode of Action}

The following summary is a short overview that does not claim to systematically review all current considerations of how hypnosis acts. Nevertheless, it should provide to the reader some insight into the lines of argumentation as well as contradictions that automatically arise following attempts to restrict discussion to causal-logic explanations within the hypnosis paradigm that - a personal opinion of the author - seems to implicitly escape too ambitious attempts to be understood by causal-logic interpretation.

It is of importance to note that no common physiological concept exists about the signal transduction pathways that mediate the effects of hypnosis. Data from experimental work sug- 
gest that hypnotic trance states are associated with spatiotemporal alterations of brain activity, skin conductance, temperature responses [13], and changes in the levels of white blood cell count, urinary catecholamines, and vanillyl mandelic acid [14]. Positron emission tomography and/or functional magnetic resonance imaging are capable of visualizing changes in cerebral blood flow during hypnotic states compared to waking behaviour $[15,16]$. Electroencephalogram (EEG) measurements revealed transient hypofrontality and left hemisphere inhibition [4], which has been deemed to be a condition of impaired information processing during hypnosis compared to the waking state [17]. This concept is similar to Ernst Hilgard's theory of neodissociation as a theoretical background of hypnosis [6]. However, observations of EEG changes are highly inconsistent between trials and do not reveal a systematically reproducible pattern of readily observable EEG changes specifically associated with hypnosis [10]. According to Fingelkurts et al. [10], this might be due to heterogeneity between trial designs and to the fact that data from most of these trials were obtained from hypnotic states achieved following hypnotic suggestions by a given operator. Thus, they do not necessarily reflect a pure hypnotic state, without any additional tasks or suggestions given to the patient. Therefore, those authors performed an EEG case study with a highly hypnotizable 39-year-old female who received a posthypnotic signal for trance induction without elaborated suggestions, which, according to these authors, reflects 'pure' hypnosis. They found a most representative and stable functional connection between the right occipital and left low-temporal cortex areas in all EEG frequency bands during hypnosis. The authors speculated that this functional link might be a neurocognitive marker of hypnosis. It might reflect the readiness of the highly hypnotizable subject to process verbal input, so that the content of the input easily turns into a hallucinated reality in visual perception.

However, data from neurobiology [e.g. 4, 10] or even first person's experience $[8,11]$ supports that there is a clear and reproducible association between the trance state and changes in cerebral blood flow, EEG, or personal experiences that can be measured easily. I.e., data show what measures finally can be changed by hypnosis, but not how these changes occur.

To get some insight into how changes could occur, Zitman et al. [18] reported that a group of patients suffering from chronic tension headache showed a continued decrease in pain intensity at 6-month follow-up as a result of explicitly labelling the hypnosis intervention, which was future-oriented imagery, as hypnosis; in contrast, a control group of patients who received exactly the same hypnosis treatment, but had not been told it was hypnosis, showed a post-treatment increase in headache pain. In other words, labelling an intervention as 'hypnosis' provided long-term benefits. Thus, we have to further ask why a word, i.e. 'hypnosis', might be effective for therapeutic purposes.

One might now speculate that therapeutic efficacy of labelling an intervention as 'hypnosis' might result from a passivereceptive and asymmetric attitude, thereby inducing age regression and infantile behaviour of the patient toward the hypnotist [7]. However, although this seems to be an acceptable rationale for being effective, the same authors also provide contradictory assumptions in their book [7]. In particular, by explaining biological mechanisms of the hypnotic trance they state the following: 'Ordinary waking behaviour follows discriminative, asymmetric cause-effect logic, referred to as "secondary process". This secondary process allows us to discriminate between subjects and to allow a subject to discover his or her identity. In contrast, dreams, some psychotic states and trance are regarded to follow a symmetric logic, according to Freud referred to as "primary process". This latter pattern of thoughts emphasizes common grounds between objects and persons with increased acceptance of contradictions and discriminations, but is associated with less emphasis on rational ideas such as "time" and "negations". Thus, the apparent contradiction lies in the declaration that hypnosis might result from passive, asymmetric behaviour of a patient toward a hypnotist, whereas the trance state is a state of symmetric common ground between both the patient and the hypnotist, with no difference between encounters. It might thus be questionable whether asymmetric behaviour between persons might reveal symmetric beneficial experiences within a given patient in the long run. However, this contradiction is restricted to the application of hypnotherapy for treatment of long-term chronic disease. It is explicitly not applicable to the apparent usefulness of direct hypnosis as adjunct to either surgery or emergency situations.

Thus, the question why the single word 'hypnosis' might provide long-term efficacy cannot be answered using classical empiric research through stressing social psychological or neurobiological mechanisms, since empiric research aims to produce data that can be ordered retrospectively according to a predefined model of what a given disease is made of. However, until now no model of how words might be effective for therapy exists. Therefore, the author finally suggests considering a shift in research methodology from pure empiric research toward heuristic research, i.e. research of how metaphors, single sentences, or even a single word might act within an individual to mediate salutogenesis.

\section{References}

1 Erickson MH, Rossi EL, Rossi SL: Hypnose: Induktion - psychotherapeutische Anwendung Beispiele. München, Pfeiffer, 1991.

- Erickson MH, Rossi EL: Varieties of double bind. Am J Clin Hypn 1975;17:143-147.
3 Erickson M: Further techniques of hypnosis-utilization techniques. Am J Clin Hypn 1959;2:3-21.

4 Gruzelier J: Redefining hypnosis: theory, methods and integration. Contemp Hypn 2000;17:51-70.
5 Weitzenhoffer AM: The Practice of Hypnotism 2000. New York, Wiley, 2000.

6 Revenstorf D: Expertise zur Beurteilung der wissenschaftlichen Evidenz des Psychotherapieverfahrens Hypnotherapie. Universität Tübingen, 2003. 
7 Revenstorf D, Peter B: Hypnose in Psychotherapie, Psychosomatik und Medizin. Manual für die Praxis. Springer, Heidelberg, 2001.

8 Rainville P, Price DD: Hypnosis phenomenology and the neurobiology of consciousness. Int J Clin Exp Hypn 2003;51:105-129.

9 Woodard FJ: A preliminary phenomenological study of being hypnotized and hypnotizing. Psycho Rep 2005;97:423-466.

10 Fingelkurts AA, Fingelkurts AA, Kallio S, Revonsuo A: Cortex functional connectivity as a neurophysiological correlate of hypnosis: an EEG case study. Neuropsychologia 2007;45:1452-1462.

11 Price DD, Barrell JJ, Rainville P: Integrating experiential phenomenological methods and neuroscience to study neural mechanisms of pain and consciousness. Conscious Cogn 2002;11:593-608.
12 Erickson MH: The seminars of Milton H. Erickson; Presentation to the San Diego Society of Clinical Hypnosis 1962. Phoenix, Arizona, Milton H. Erickson Foundation Press 2001;1:1-34.

13 Barabasz AF: Schnelle neuronale Aktivierung (IANP): reduzierte Stimulation und psychophysiologische Aufzeichnungen bei der Behandlung eines phobischen Piloten. Exp Klin Hypn 1994;10: 167-176.

14 Bongartz W, Lyncker I, Kossman K: The influence of hypnosis on white blood cell count and urinary levels of catecholamines and vanillyl mandelic acid. Hypnos 1987;14:52-61.
15 Carter CS, Mintun M, Cohen JD: Interference and facilitation effects during selective attention: an H2150 PET study of Stroop task performance. Neuroimage 1995;2:264-272.

16 Chen AC: New perspectives in EEG/MEG brain mapping and PET/fMRI neuroimaging of human pain. Int J Psychophysiol 2001;42:147-159.

17 Dietrich A: Functional neuroanatomy of altered states of consciousness: the transient hypofrontality hypothesis. Conscious Cogn 2003;12:231-256.

18 Zitman FG, Van Dyck R, Spinhoven P, Linssen AC: Hypnosis and autogenic training in the treatment of tension headaches: a two-phase constructive design study with follow-up. J Psychosom Res 1992; 36:219-228. 